\title{
Patterns of seasonal maximum snow-water equivalent over the Northern Great Plains of the United States analyzed using hybrid-modeled climatology
}

\author{
Andrew Grundstein* \\ Climate Research Laboratory, Department of Geography, University of Georgia, Athens, Georgia 30602-2502, USA
}

\begin{abstract}
Over the last 20 yr across North America, satellite and in situ observations have indicated a reduction both in the number of snow-cover days and in snow-cover extent in the spring. From a hydrologic perspective, however, the water content of the snowpack is most important. Few studies have examined whether the changes in snow-cover days or snow-cover extent corresponded to changes in the water content of the snowpack. This is due largely to the problems with obtaining quality data on the snow-water equivalent (SWE). This paper uses a long-term, high-resolution hybrid SWE climatology to examine peak seasonal SWE and its impact on the hydrology of the Northern Great Plains. Accumulations of peak SWE, most frequently occurring in February, are greatest over NE Minnesota and decrease towards the south and southwest. There are no long-term trends in the magnitude of SWE, but there are distinct decadal-scale patterns of above- and below-average SWE. In general, the 1950s were below average, the mid-1960s through the 1970s were above average, and the 1980s and early 1990s were again below average. Greater maximum seasonal SWE corresponds with longer snow persistence in the spring and greater March snow-cover area.
\end{abstract}

KEY WORDS: Snow-water equivalent $\cdot$ Snow hydrology $\cdot$ Northern Great Plains

Resale or republication not permitted without written consent of the publisher

\section{INTRODUCTION}

Simulations of anthropogenic climate change indicate that increasing concentrations of greenhouse gases may have considerable impacts on the cryospheric portion of the water budget. Studies suggest that the duration of snow cover may decrease by up to $40 \%$ in the Canadian Prairies and $70 \%$ in the Great Plains (Boer et al. 1992, Brown et al. 1995). Such changes can have dramatic impacts on local hydrology. An earlier onset of spring snowmelt in many regions of North America has been linked to a shift of maximum streamflow to earlier dates (Burn 1994, Groisman et al. 2001). In states such as North and South Dakota much of the spring runoff is generated by melting snow. Since many areas within these states depend on surface water for their water-resource needs, changes in the timing and amount of runoff could have important consequences.
Both in situ and satellite-derived observations of snow cover over North America have revealed a distinct trend in changing snow cover over time. Through the late 1980s and early 1990s, satellite-derived snowcover data indicates that annual snow-cover extent declined over North America (Robinson \& Dewey 1990, Groisman et al. 1994). Further, studies indicate that most of this decrease has occurred during the spring and corresponds with an increase in springtime temperatures (Groisman et al. 1994). Since satellitederived observations of snow cover extend to only the last $30 \mathrm{yr}$, others have incorporated in situ data to extend the record back to the turn of the century (Hughes \& Robinson 1996, Frei et al. 1999). Hughes \& Robinson (1996), using measurements from cooperative observing stations, found a similar trend in their analysis of the Central and Northern Great Plains region of the United States. Since the 1970s, they 
noticed a shift towards a shorter spring duration of snow cover. Frei et al. (1999) combined both satellite and station observations to examine snow-cover extent back to 1900 . They found that since the 1950s there has been a decrease in March snow-cover extent. The earlier retreat of spring snow cover has been documented to impact spring runoff. For instance, Groisman et al. (2001) have observed a steady runoff increase in the month of maximum streamflow in the Mississippi River Basin. They attribute this to a gradual shift of runoff of snowmelt to earlier dates.

Most long-term studies of snow have focused simply on the presence of snow and not the actual water content. From a hydrologic perspective, the water content of a snowpack or snow-water equivalent (SWE) is a more useful variable, because it provides an estimate of the water that will become available for runoff in the spring. In part, SWE has not been used for climate studies because of the poor quality of the data. Climate studies of regional or hemispheric scale need spatially and temporally extensive data. In the United States, the National Weather Service (NWS) has taken point measurements of SWE since the winter of 1948/49 at its first-order observing stations. Unfortunately, the network of stations is not sufficiently dense to capture the great variability of SWE across regions. In addition, Schmidlin (1990) documented a number of problems with the NWS data including digitizing errors and the use of sampling sites that are unrepresentative of surrounding terrain. Remote-sensing techniques, relying on microwave radiometers, have increasingly been used to produce SWE estimates with greater spatial coverage. A number of different algorithms have been developed to relate the attenuation of microwaves from the underlying ground surface and the water content of the snowpack (Chang et al. 1987, Goodison \& Walker 1995). Under certain circumstances these algorithms do not perform well. The presence of liquid water in the snowpack or certain land-use types such as coniferious forests can affect the microwave emission and lead to erroneous estimates (Hall et al. 1982, Walker \& Goodison 1993, Tait 1996). Further, remotely sensed estimates have only been available since the late 1970s and early 1980s, and do not provide a sufficiently long time series for climatic analysis. Aircraft have also been used to directly measure SWE by sensing the attenuation of natural gamma radiation. The airborne survey program, operated by the Office of Hydrology of the National Weather Service, estimates SWE over more than 1500 flight lines in the United States and Canada during the snow-cover season (Carroll \& Carroll 1993). Since flights are only made at the request of local NWS offices for use in such work as flood forecasting, the SWE data is of insufficient consistency for climate research (Schmidlin 1990).
Additionally, problems in interpreting the data can occur due to deep mountain snowpacks, which can greatly attenuate the gamma radiation, due to variability of the snowpack along the flight line, or if soilmoisture levels change significantly from the time of the initial calibration flight (Foster et al. 1987, Carroll \& Carroll 1989).

This project will attempt to fill this gap in research on SWE by using a long-term, high-resolution climatology of SWE that is derived from a combination of model output and snow-depth observations. In this method, snowpack densities are generated by a mass- and energy-balance snowpack model. The modeled snow densities are then used in conjunction with snow depths from stations providing daily observations to compute SWE values. A hybrid approach to generating the climatology was used because it utilizes the advantages of each source of snow-cover information. Model-generated output provides for a long and complete time series of snow properties such as density. The great spatial variability in snow cover and subsequently SWE can be captured in the climatology by incorporating the large number of snow depth observations into the final product. This new SWE climatology, then, will be used to examine whether the changes in snow-cover extent that have been observed recently correspond with any change in the water content of the snowpack. The first part of this paper will present the spatial and temporal patterns of peak seasonal SWE. Next, inter-annual variations in peak seasonal SWE will be explored. Finally, a case study of the Red River watershed will be used to illustrate the link between seasonal maximum SWE and spring and summer runoff.

\section{DATA AND METHODOLOGY}

This project uses a high-resolution, $1^{\circ} \times 1^{\circ}$ hybrid SWE climatology that encompasses a 5-state region in the Northern Great Plains (Fig. 1). The climatology, extending from 1951/52 through to 1998/99, was generated using a physically based snowpack model (SNTHERM version 4; Jordan 1991) in conjunction with snow depths from several hundred cooperative observing stations. The climatology has been found to capture both the spatial variability and magnitude of SWE well (Grundstein et al. 2003, Mote et al. 2003). In the first portion of the study, these SWE values are used to study the spatial and temporal patterns of seasonal maximum or peak SWE for the snow-cover season from November through April. Peak seasonal SWE was used because it represents the maximum amount of water that accumulates in the snowpack and is subsequently available for runoff. To create a map of 


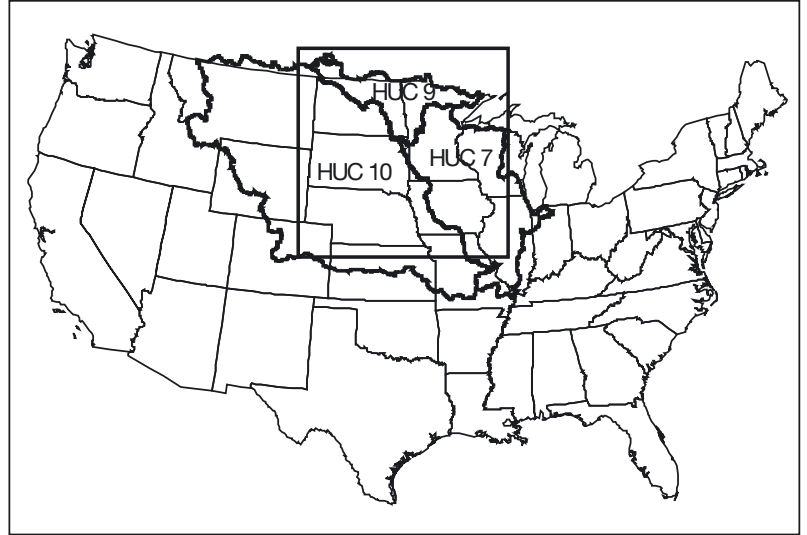

Fig. 1. Northern Great Plains study region (boxed) and hydrologic subregions: northern (HUC 9), eastern (HUC 7), and western (HUC 10). HUC: USGS hydrologic unit code

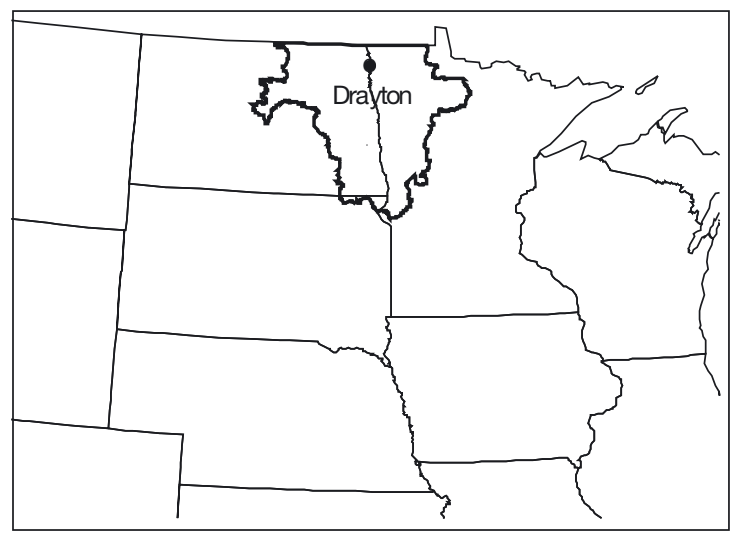

Fig. 2. Red River watershed (HUC 0902) and location of the USGS stream gauge $(\bullet)$

maximum SWE, an annual series of peak SWE was created for each grid cell. From this annual series, summary statistics were calculated.

Interannual patterns of the magnitude and timing of maximum SWE were examined for 3 hydrologically defined sub-regions within the Northern Great Plains. These sub-regions were selected using a system developed by the United States Geological Survey (USGS) in which areas in the United States were divided into hydrologic units and identified by a unique hydrologic unit code (HUC) (Seaber et al. 1987). The Northern Great Plains is divided into 3 major hydrologic regions. Drainage from the Western region (HUC 10) feeds into the Missouri River; the Northern region (HUC 9) into the Souris, Red, and Rainy Rivers; and the Eastern region (HUC 7) into the Mississippi River (Fig. 1). As shown in Fig. 1, the SWE data covers nearly the entire Northern region but only portions of the Eastern and Western regions. For the SWE data contained in each region, an areally weighted average was computed. From these regional averages, the date and magnitude of peak seasonal SWE was identified.

In the third portion of the study, an individual watershed (HUC 0902) from the Northern region is used as a case study for illustrating the link between seasonal peak SWE and streamflow in the spring (Fig. 2). The Red River watershed covers $80000 \mathrm{~km}^{2}$ and feeds into the Red River of the north, where daily streamflow data from a gauging station located at Drayton, ND were used (Fig. 2). These data were obtained from the United States Geological Survey (http://waterdata. usgs.gov/nwis).

\section{SPATIAL AND TEMPORAL PATTERNS OF PEAK SEASONAL SWE}

The Northern Great Plains is characterized by ephemeral winter snow cover that builds through the winter and melts in the later winter and spring. This section will examine the temporal patterns maximum seasonal SWE. Since the Northern Great Plains is characterized by intra-regional hydrologic and climatic variability, peak seasonal SWE values were aggregated among 3 hydrologically defined sub-regions (Fig. 1). To establish a baseline as to when the maximum SWE most frequently occurs, the date of maximum SWE for each sub-basin was sorted by month. The northernmost region has the lowest wintertime temperatures, and the snowpack generally is able to build through the winter (Fig. 3). Thus, 90\% of the peak SWE occurs in January, February, and March. Of those 3 months, February has by far the greatest frequency of peak SWE, with nearly $50 \%$. The Eastern region and especially the Western region tend to have more ephemeral snow cover, and 1 large snowfall event can lead to a seasonal maximum. Thus, both regions have peak SWE occurring at a greater frequency both earlier in the season (November and December) and later in the season (April) than the Northern region (Fig. 3). Nevertheless, $80 \%$ of the peak SWE days in the Eastern region and $90 \%$ of these days in the Western region occur in January and February.

In addition to variations in the timing of maximum SWE, there is also a distinct spatial pattern to maximum seasonal SWE. Here, an analysis of the spatial distribution of peak SWE is accomplished by creating an annual series of peak SWE for each grid cell. The average and standard deviation of the $49 \mathrm{yr}$ time series for each grid cell is then plotted and contoured (Fig. 4). The largest accumulated peak SWE values, exceeding $100 \mathrm{~mm}$, are present over the NE corner of Minnesota (Fig. 4A). The magnitude of SWE declines significantly 


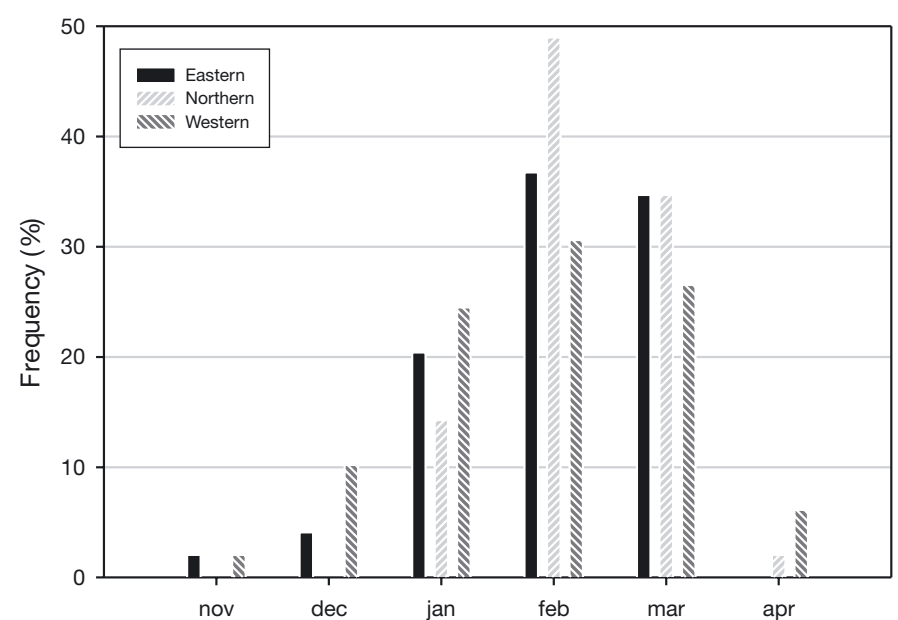

Fig. 3. Temporal patterns of seasonal maximum snow-water equivalent (SWE) for the Eastern, Northern, and Western hydrologic regions

across a sharp transition zone extending in a NE-SW direction over NE Minnesota. After this point, SWE declines more gradually to the west and southwest, where the average water content of the snow cover is $<40 \mathrm{~mm}$. There is, of course, considerable variability in the peak SWE from one year to the next. With a larger average value, the northern quadrant of the study area also has a larger standard deviation, exceeding $50 \mathrm{~mm}$ (Fig. 4B). That value declines to $30 \mathrm{~mm}$ across areas over western Nebraska and SE South Dakota that have smaller seasonal peak SWE values.

\section{ANNUAL SERIES OF THE TIMING AND MAGNITUDE OF SEASONAL MAXIMUM SWE}

This section of the study examines the interannual patterns of the magnitude and timing of peak seasonal SWE in each of the hydrologically defined subregions. The time series of peak SWE was generated by identifying the day with the largest regionally averaged SWE for that season. A 9 yr moving average was applied to smooth the data.

\subsection{Northern region}

The Northern region in this study encompasses a watershed extending across North Dakota and Minnesota as well the southern portions of Manitoba and Ontario, Canada. The drainage in this watershed feeds into the Red, Souris, and Rainy Rivers. The average regional peak SWE is $75 \mathrm{~mm}$ but has varied between $169 \mathrm{~mm}$ in 1969 and $21 \mathrm{~mm}$ in 1958 (Fig. 5A). A time series of seasonal maximum water content reveals no long-term trend but distinct multi-year cycles in the 1951-1999 period. The first period extends from the 1950s through the mid-1960s and is characterized by below-average SWE accumulations. A second period, extending from the mid-1960s through the 1970s, has above-average peak SWE accumulations. The 2 greatest SWE accumulations, $169 \mathrm{~mm}$ in 1969 and $154 \mathrm{~mm}$ in 1979, occurred during this period. Finally, the third period occurs between 1980 and the early 1990s and marks a return to a below-normal period in seasonal SWE accumulation.

The peak SWE tends to occur at the end of February (Day 53) but has occurred as early as 11 January in 1973 or as late as 5 April in 1996 (Fig. 5B). There are 2 notable multi-decadal periods in the time series. From 1951 through to 1980, nearly two-thirds of the years had peak SWE later than the long-term mean value of Day 53. The 19 yr period from 1981 through to 1999 includes 14 years with maximum seasonal SWE occurring on a date earlier than normal. The explained variation between the date of maximum SWE and the amount of SWE is low $\left(\mathrm{r}^{2}=0.09\right)$, and one can see the considerable amount of scatter in Fig. 5C.
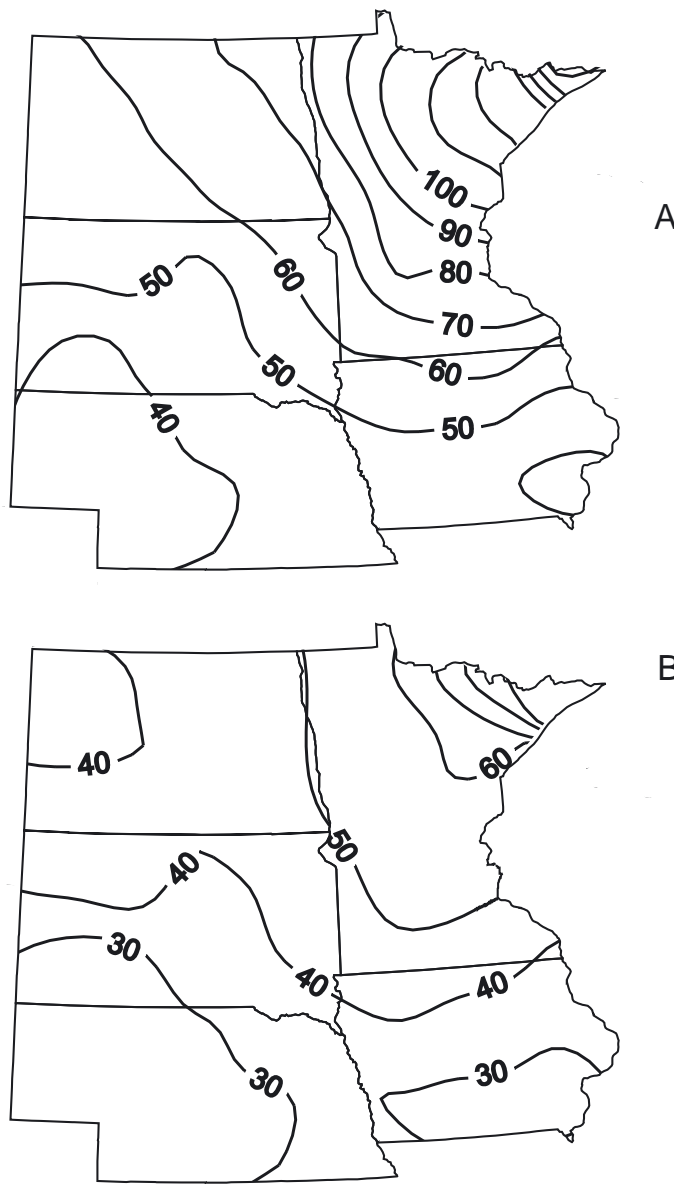

Fig. 4. Spatial patterns of seasonal maximum SWE (mm): (A) mean and (B) standard deviation 

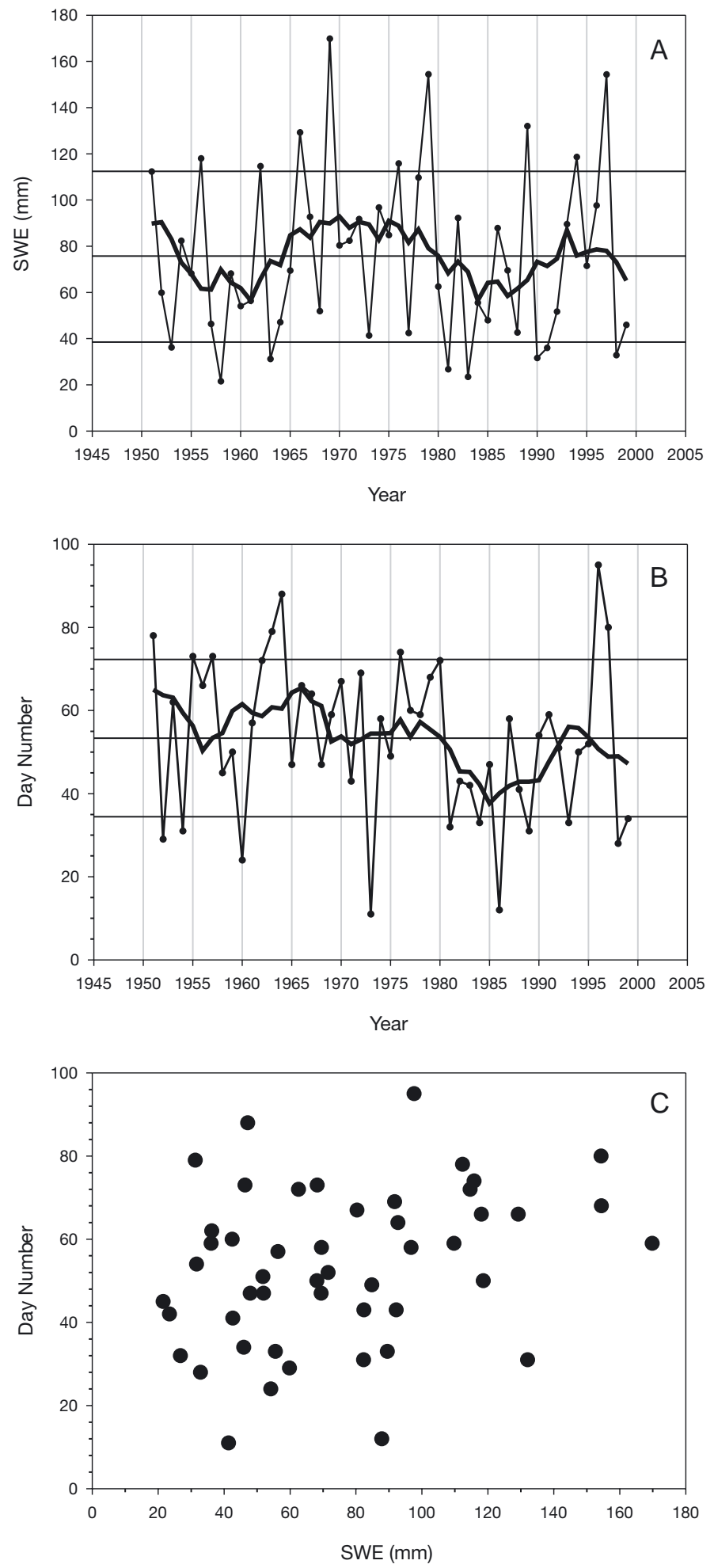

Fig. 5. Seasonal maximum SWE for the Northern region. (A) Annual series of SWE magnitude; (B) annual series of the day number on which the peak SWE occurs; (C) relationship between SWE magnitude and peak day number. In (A) and (B) the heavy solid line is a 9 yr moving average; the upper, middle, and lower horizontal lines are $+1 \mathrm{SD}$, mean, and $-1 \mathrm{SD}$, respectively

\subsection{Eastern region}

The Eastern region in this study covers the southern portions of Minnesota and most of Iowa and consists of a watershed that ultimately drains into the Mississippi River. The mean peak SWE is nearly one-quarter less than that for the Northern region at $51 \mathrm{~mm}$ (Fig. 6A). The amount of SWE, however, can vary considerably, from as little as $13 \mathrm{~mm}$ in 1981 to as much as $135 \mathrm{~mm}$ in 1979. As in the Northern region, there is no long-term trend in the magnitude of peak SWE but several multiyear periods. The period from the mid-1950s to the mid-1960s had below-average SWE. A second $20 \mathrm{yr}$ period extends from 1965 to 1984 . This period is characterized by higher interannual variability in peak SWE. Overall, the mean SWE during this period is $59 \mathrm{~mm}$, compared with $51 \mathrm{~mm}$ for the long-term mean, and the standard deviation is higher at $34 \mathrm{~mm}$, compared with $30 \mathrm{~mm}$. In the third period, 1985-1999, there is below-average SWE, with 10 of the 15 years having peak SWE less than $51 \mathrm{~mm}$.

The timing of peak seasonal SWE can vary considerably from one year to the next but on average occurs in the middle of February (Day 44) (Fig. 6B). The earliest peak SWE occurred on 20 November (Day 83) in 1965 and the latest on 24 March (Day 324) in 1987. In this region, 4 main periods are evident. In the first period, $1951-1965,67 \%$ (10 of 15) of the years had later-thannormal peak accumulation of SWE. In all 10 of those years, the peak SWE occurred in March, over $2 \mathrm{wk}$ later than the long-term mean date. The next period, 1965-1973, has earlier than average dates for maximum seasonal SWE in 6 of the 8 years. The third period is a $4 \mathrm{yr}$ period in the late 1970s with consecutive years of later-than-normal peak accumulations, generally occurring in March. The fourth period, extending from 1981 through the early 1990s, is notable for having years with anomalously early peak SWE. A linear regression analysis of the time series indicates a statistically significant trend (at the $95 \%$ confidence level) towards peak SWE occurring earlier in the season. The trend is $5.7 \mathrm{~d} \mathrm{decade}^{-1}$. Similar to the Northern region, the explained variation between the date of maximum SWE and the amount of SWE is fairly low $\left(\mathrm{r}^{2}=0.10\right)$ and is illustrated by the considerable amount of scatter in Fig. 6C.

\subsection{Western region}

For this study, the Western region is a watershed that includes eastern portions of North Dakota and Iowa as well as all of South Dakota and Nebraska. Melting snow and rainfall in this watershed ultimately flow into the Missouri River. This region has the smallest peak 

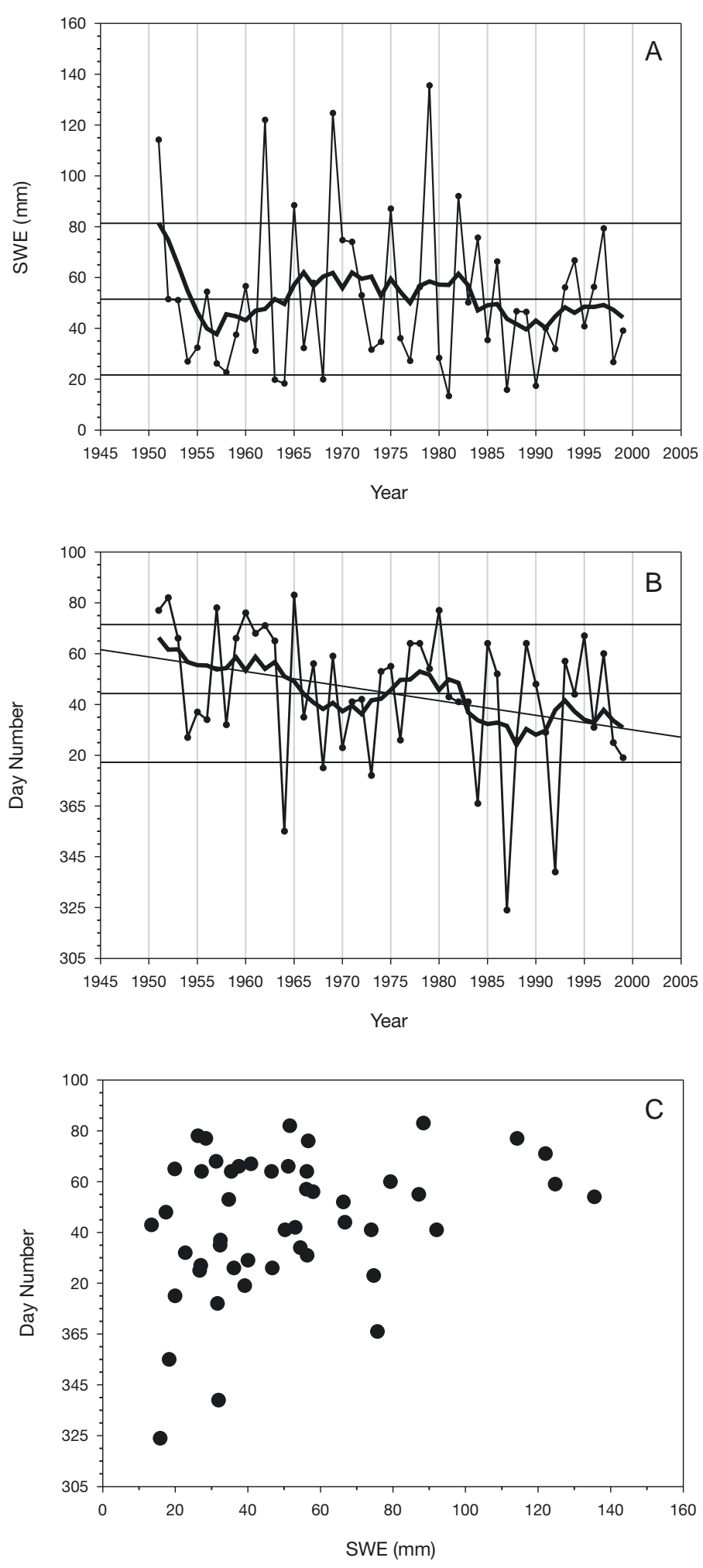

Fig. 6. Seasonal maximum SWE for the Eastern region. (A) Annual series of SWE magnitude; (B) annual series of the day number on which the peak SWE occurs; (C) relationship between SWE magnitude and day number. Lines as in Fig. 5 seasonal SWE of the 3 regions, with a mean value of $29 \mathrm{~mm}$ (Fig. 7A). A maximum seasonal SWE of $78 \mathrm{~mm}$ occurred in 1969, and a minimum value of $6 \mathrm{~mm}$ occurred in 1981. As with the other 2 study regions, there is no long-term trend in maximum seasonal SWE but a few noticeable patterns. The 1950s through the 1960s is a period with below-average SWE. The next period, 1969-1979, is not distinguished by the frequency of above- and below-normal years but rather by having 3 years with the greatest SWE $(1969,1978$, and 1979). The 1980s and 1990s represent a return to below-normal SWE, where 6 of the lowest 10 peak SWE values occurred in this period.

The mean time of maximum seasonal accumulation is the earliest of the 3 regions and occurs in the first half of February (Day 42; Fig. 7B). The earliest peak accumulation over the 49 yr study period was 2 November 1992, and the latest occurred on 12 April 1995. The 1960s and early 1970s are characterized by earlier-than-normal peak accumulations of SWE. From 1975 through 1980, later peak accumulations of SWE occurred in 4 of the 5 years. An earlier-than-normal peak accumulation also occurs through the 1980s and early 1990s. Of the 3 regions, this one has the smallest explained variation between the date of maximum SWE and the magnitude of SWE $\left(r^{2}=0.03\right.$; Fig. $\left.7 C\right)$.

\section{CASE STUDY OF SNOW HYDROLOGY IN THE RED RIVER WATERSHED}

From the previous sections, it is clear that there are substantial interannual variations in the magnitude and timing of peak seasonal SWE accumulations. The total water content of the snowpack and the timing of its ablation in the late winter and spring have particularly important impacts on spring streamflow runoff in many areas of the Northern Great Plains. Thus, the study of the amount of snow rather than its mere presence is essential for understanding regional hydrology. The high-resolution hybrid SWE climatology allows for a more representative accounting of SWE in the watershed, and thus a better assessment of the relationship between seasonal snow accumulation and springtime streamflow runoff. The Red River watershed, encompassing parts of North Dakota and Minnesota, has a particularly strong snow hydrology component and will be used as a case study. It is also an area that is frequently subject to devastating snowmelt-induced floods, mostly notably in 1997.

The Red River watershed (HUC 0902), encompassing over $80000 \mathrm{~km}^{2}$, falls within the Northern area and drains into the Red River of the north (Fig. 2). On average, the watershed is characterized by a single seasonal peak in discharge that occurs following the 

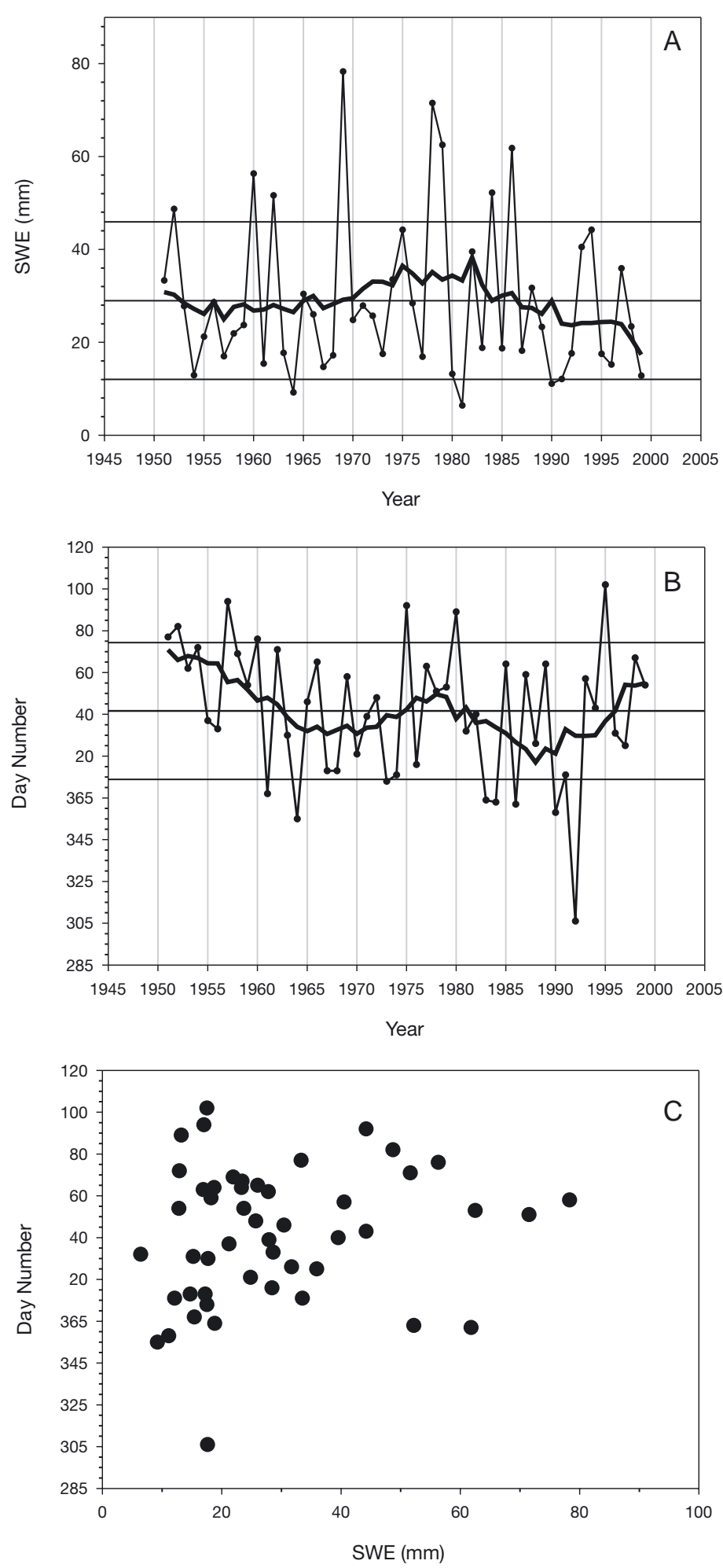

Fig. 7. Seasonal maximum SWE for the Western region. (a) Annual series of SWE magnitude; (B) annual series of the day number on which the peak SWE occurs; (C) relationship between SWE magnitude and day number. Lines as in Fig. 5
Table 1. Years with anomalous maximum seasonal SWE for a watershed feeding into the Red River of the north and day of year with no snow. Day is from 1 (1 January) to 365 (31 December)

\begin{tabular}{|cccc|}
\hline & Year & Maximum SWE $(\mathrm{mm})$ & Day of year \\
\hline Low SWE & 1958 & 10 & 85 \\
& 1963 & 13 & 83 \\
& 1981 & 14 & 73 \\
& 1983 & 11 & 78 \\
& 1990 & 25 & 97 \\
High SWE & 1969 & 15 & 83 \\
& 1979 & 150 & 104 \\
& 1989 & 152 & 112 \\
& 1994 & 129 & 106 \\
& 1997 & 134 & 92 \\
& Mean & 195 & 116 \\
& & 152 & \\
\hline
\end{tabular}

ablation of the snowpack between March and May. To examine the role of anomalous SWE on spring and summer streamflow, the years with the highest 5 and lowest 5 regional average peak SWE values were selected (Table 1). In general, these 10 years match very closely with those of the larger Northern region that encompasses it. This watershed, on average, has a maximum seasonal SWE of $67 \mathrm{~mm}$, with a standard deviation of $40 \mathrm{~mm}$. The 5 years with the greatest peak SWE average $152 \mathrm{~mm}$ and have snow that persists until the middle of April (Day 106). The 5 years with the lowest SWE average only $15 \mathrm{~mm}$ of SWE and have snowpacks that persist on average until the end of March (Day 83).

Fig. 8A, a graph of the daily SWE for each of these years, helps to illustrate both the magnitude of SWE and the timing of its accumulation and ablation. In the highest 5 SWE years, one can see the large amount of snow mass present late into the season. With the higher sun angles and intrusions of warmer air masses, the snowpacks melt rapidly at the end of March and in April, releasing large quantities of water into the stream system. In contrast, the lowest 5 SWE years have little accumulated snow mass at any time in the season. With a smaller accumulated snow mass, less energy is needed for snowmelt, and therefore ablation tends to occur earlier in the season. Furthermore, when they do melt, there is less water released into the watershed.

The impact of this melt water on the hydrology can be examined by looking at daily streamflow data, which has been smoothed using a $28 \mathrm{~d}$ moving average (Fig. 8B). The highest 5 SWE years have very distinct streamflow maxima in April and early May. Furthermore, the magnitude of streamflow, ranging between 20000 and $70000 \mathrm{cfs}\left(5.6 \times 10^{5}\right.$ to $\left.1.98 \times 10^{6} \mathrm{l} \mathrm{s}^{-1}\right)$, cor- 

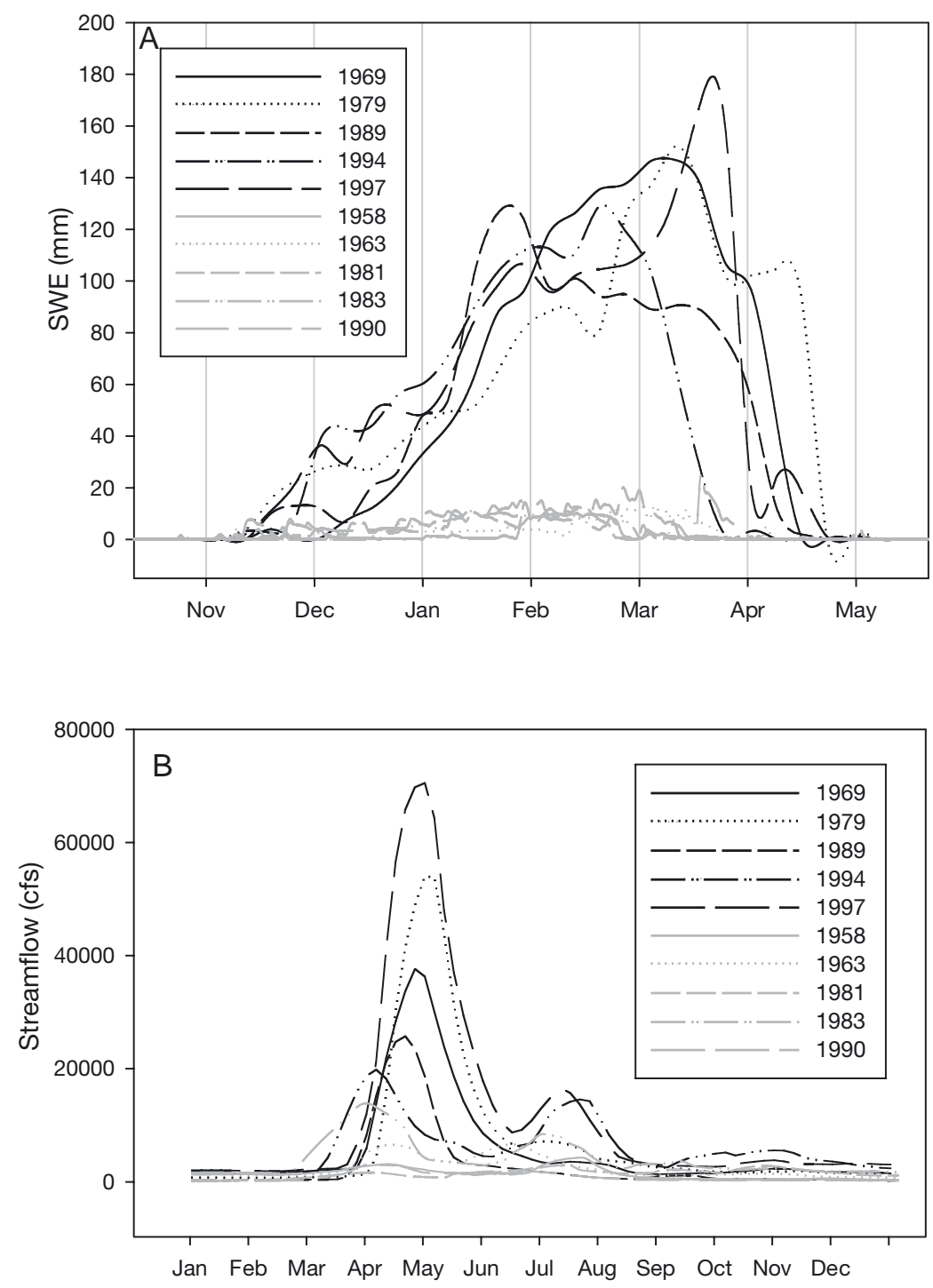

Fig. 8. Snow hydrology in a watershed feeding into the Red River of the north. (A) Daily SWE accumulation; (B) 28 d moving average of dailystreamflow

responds closely with the large amount of melt water that was released. Of the years with the lowest peak SWE, only 1963 and 1983 have any discernable maximum daily streamflow. These streamflow maxima occur earlier, principally in late March and early April. Also, the magnitude of daily streamflow is considerably smaller than in years with high SWE, with daily peak flows for most years under $6000 \mathrm{cfs}\left(1.7 \times 10^{5} 1 \mathrm{~s}^{-1}\right)$

\section{DISCUSSION AND CONCLUSION}

Snow is a variable that closely interacts with both the water and energy budgets of an area. It is also an excellent indicator of climate change because it is sen- sitive to changes in both temperature and precipitation. Up to this point, a great deal of research has been conducted on variations in snow-cover extent or snow-cover persistence but little on the water content of the snowpack, which has such an important impact on the water budget of an area. This paper addressed this problem by using a hybrid climatology of SWE that incorporated both model output and data from cooperative observing stations. Maximum seasonal SWE was examined both in a climatological sense to establish baseline values and for the study of interannual variations.

The interannual SWE patterns, produced for portions of 3 major watersheds in the Northern Great Plains, can help complete the picture of how the snowpack and snow cover are changing over time. As mentioned earlier, studies using both remotely sensed and in situ observations have noted that snow-cover days and snow-cover extent have varied considerably over the century (Brown \& Goodison 1996, Hughes \& Robinson 1996, Frei et al. 1999). Of more concern is that over the last 20 yr there has been a retreat in the extent of Northern Hemisphere spring snow cover (Grosiman et al. 1994, Robinson \& Frei 2000).

In all 3 hydrologic regions there is no longterm trend in seasonal maximum SWE but there are distinct multi-year patterns. Relative to the 1950-1999 mean seasonal maximum SWE, the 1950s were a below-average period, the mid-1960s to the mid-1970s were above average, and the 1980s through the early 1990s were a return to below-average values. The multi-year patterns in peak seasonal SWE appear to correspond with the cycles in spring snow-cover days observed by Hughes \& Robinson (1996). They found that the 1960s and 1970s were characterized by a high number of days in the spring and fewer snow days in the 1980s and early 1990s. With the above-average SWE in much of the 1960s and 1970s, it is not surprising that there was an increase in days with snow cover. The greater amount of snow would take longer to ablate and therefore persist longer into the season. Similarly, the reduced amount of SWE that accumulated in much of the 1980s and early 1990s means that there was less snow to melt and therefore an earlier melt-off date. An examination of snow persistence in the Red River watershed shows that the average date of zero snow on the ground on average is more than $20 \mathrm{~d}$ later during the years with the highest 5 peak SWE accumulations than during those with the 5 lowest (Table 1). 
Table 2. Years with anomalous maximum seasonal SWE for the Northern and Eastern watersheds. SWE is the seasonal maximum in $\mathrm{mm}$ and March SCA is the average monthly snow-cover area in $\mathrm{km}^{2}$

\begin{tabular}{|c|c|c|c|c|c|c|}
\hline & \multicolumn{3}{|c|}{ Northern } & \multicolumn{3}{|c|}{ Eastern } \\
\hline & Year & SWE & March SCA & Year & SWE & March SCA \\
\hline \multirow[t]{6}{*}{ High SWE } & 1969 & 170 & 154333 & 1969 & 125 & 339614 \\
\hline & 1979 & 154 & 154333 & 1975 & 87 & 365657 \\
\hline & 1989 & 132 & 146299 & 1979 & 136 & 389461 \\
\hline & 1994 & 119 & 107742 & 1982 & 92 & 280647 \\
\hline & 1997 & 154 & 154333 & 1997 & 79 & 231323 \\
\hline & Mean & 146 & 143408 & Mean & 104 & 321340 \\
\hline \multirow[t]{6}{*}{ Low SWE } & 1981 & 27 & 9052 & 1968 & 20 & 128723 \\
\hline & 1983 & 23 & 104555 & 1981 & 13 & 61844 \\
\hline & 1990 & 32 & 82678 & 1987 & 16 & 103141 \\
\hline & 1991 & 36 & 68880 & 1990 & 17 & 86182 \\
\hline & 1998 & 33 & 121350 & 1998 & 27 & 284362 \\
\hline & Mean & 30 & 77303 & Mean & 19 & 132850 \\
\hline
\end{tabular}

It is more difficult to directly relate this study to previous studies of snow-cover area because the study regions do not completely overlap. To address this problem, snow-cover-area data, used in Robinson et al. (1993) and Robinson \& Frei (2000), was re-sorted to exactly cover each of the 3 hydrologic regions (Northern, Eastern, and Western) used in this study. This dataset is derived from visible satellite imagery and extends from 1967 through to 2002 (data courtesy of the Rutgers Climate Lab). Only in the Northern watershed does the SWE data coverage extend across nearly the whole watershed. The SWE data in the Eastern watershed covers only a portion of the total watershed, but since it extends in a north-south orientation, it presents a reasonable index of the amount of SWE present across the whole watershed. In both cases, there is a strong statistical relationship between maximum seasonal SWE and average March snow-cover area. The correlation coefficient between these 2 variables is 0.64 in the Northern region and 0.67 in the Eastern region.

An examination of years with the 5 greatest and 5 lowest peak SWE accumulations in 1967-1999 illustrates that years with the largest (smallest) accumulations of SWE are also associated with greater (smaller) March snow-cover areas (Table 2). Indeed, average March snow-cover area for the years with the greatest maximum seasonal SWE is over twice as large as during the years with the least seasonal maximum SWE. The coefficient of variation (standard deviation/mean), however, is much smaller for the years with the largest accumulations (0.14 and 0.20 for the Northern and Eastern regions, respectively) compared to years with the smallest values ( 0.55 and 0.66 for the Northern and Eastern regions, respectively). This suggests that the conditions that lead to large SWE accumulations also consistently produce widespread snow cover.
The current SWE dataset only extends over a 5-state area in the Northern Great Plains. Presently, this dataset is being expanded to cover eastern North America. It is hoped that with the completion of this dataset, a more comprehensive examination of variations in North American snow and its interactions with regional hydrology can be made.

Acknowledgements. This work was supported by a grant from NASA (NAG5-11592).

\section{LITERATURE CITED}

Boer GJ, McFarlane N, Lazare M (1992) Greenhouse gasinduced climate change simulated with the CCC secondgeneration general circulation model. J Clim 5:1045-1077

Brown R, Hughes M, Robinson D (1995) Characterizing the long term variability of snow cover extent over the interior of North America. Ann Glaciol 21:45-50

Brown RD, Goodison BE (1996) Interannual variability in reconstructed Canadian snow cover, 1915-1992. J Clim 9: 1299-1318

Burn DH (1994) Hydrologic effects of climatic change in West-Central Canada. J Hydrol 160:53-70

Carroll SS, Carroll TR (1989) Effect of uneven snow cover on airborne snow water equivalent estimates obtained by measured terrestrial gamma radiation. Water Resour Res 25:1505-1510

Carroll SS, Carroll TR (1993) Increasing the precision of snow water equivalent estimates obtained from spatial modeling of airborne and ground based snow data. In: Proc 50th Eastern Snow Conference, Quebec City, p 83-87

Chang ATC, Foster JL, Hall DK (1987) Nimbus-7 derived global snow cover parameters. Ann Glaciol 9:39-44

Foster JL, Hall DK, Change ATC (1987) Remote sensing of snow. EOS 68:682-684

Frei A, Robinson D, Hughes M (1999) North American snow extent: 1900-1994. Int J Climatol 19:1517-1534

Goodison BE, Walker AE (1995) Canadian development and use of snow cover information from passive microwave satellite data. In: Choudhury BJ, Kerr YH, Njoku EG, Pam- 
paloni P (eds) Passive microwave remote sensing of land-atmosphere interactions. VSP, Utrecht, p 245-262

Groisman P, Karl TR, Knight RW (1994) Observed impact of snow cover on the heat balance and the rise of continental spring temperatures. Science 263:198-200

Groisman PY, Knight RW, Karl TR (2001) Heavy precipitation and high streamflow in the contiguous United States: trends in the twentieth century. Bull Am Meteorol Soc 82: 219-246

Grundstein A, Mote T, Leathers D (2003) A hybrid climatology of snow water equivalent across the Northern Great Plains of the United States. Polar Geogr (in press)

Hall DK, Foster JL, Chang ATC (1982) Measurement and modeling of microwave emission from forested snowfields in Michigan. Nord Hydrol 13:129-138

Hughes MG, Robinson DA (1996) Historical snow cover variability in the Great Plains region of the United States: 1910 through 1993. Int J Climatol 16:1005-1018

Jordan R (1991) A one dimensional temperature model for snow cover: technical documentation for SNTHERM.89. Special Report 91-16. US Army Corps of Engineers, Cold Regions Research and Engineering Laboratory, Hanover, $\mathrm{NH}$

Mote TL, Grundstein AJ, Leathers DJ, Robinson DA (2003) A comparison of modeled, remotely sensed, and measured

Editorial responsibility: Robert Davis,

Charlottesville, Virginia, USA snow water equivalent in the Northern Great Plains. Water Resour Res (in press)

Robinson DA, Dewey KF (1990) Recent secular variations in the extent of Northern Hemisphere snow cover. Geophys Res Lett 17:1557-1560

Robinson DA, Frei A (2000) Seasonal variability of Northern Hemisphere snow extent using visible satellite data. Prof Geogr 52:307-315

Robinson DA, Dewey KF, Heim R Jr (1993) Global snow cover monitoring: an update. Bull Am Meteorol Soc 74: 1689-1696

Schmidlin TW (1990) A critique of the climatic record of water equivalent on the ground in the United States. J Appl Meteorol 29:1136-1141

Seaber PR, Kapinos FP, Knapp GL (1987) Hydrologic unit maps. US Geologic Survey Paper 2294. United States Government Printing Office, Washington, DC (also available at: http://water.usgs.gov/pubs/wsp/wsp2294/html/pdf.html)

Tait A (1996) Estimation of snow water equivalent using passive microwave radiation data. In: Proc 1996 Int Geoscience and Remote Sensing Symposium, Lincoln, NE, May 1996. p 2005-2007

Walker AE, Goodison BE (1993) Discrimination of a wet snow cover using passive microwave satellite data. Ann Glaciol $17: 307-311$

Submitted: October 11, 2002; Accepted: April 28, 2003

Proofs received from author(s): June 30, 2003 